\title{
VARIEDADES
}

\section{NOTAS SOBRE LA RELACIÓN DE MOROS DE LA ALJAMA DE ZARAGOZA Y CONVERSOS DE SU COMUNIDAD (SIGLO XV)}

\author{
ENCARNACIÓN MARÍN PADILLA \\ CSIC, Madrid
}

Si la documentación notarial que alude al tema de la relación judeoconversa durante el siglo XV en Aragón, incluidos los intrumentos públicos de testamento, es abundante y rica, no puede decirse lo mismo de la que se refiere a la que sostuvieron los moros con los conversos provenientes de sus propias comunidades.

No es la primera vez que comento que los testamentos proporcionan datos fehacientes de esa relación y que las noticias documentales que aportan los que otorgaron los miembros de las comunidades de moros y quienes de sus aljamas se bautizaron, son escasas y escuetas si se comparan con las que proporcionan las últimas voluntades de cristianos viejos y judíos o de neófitos y conversos del judaísmo.

Dos son las razones principales: la infrecuente comparecencia de los componentes de las comunidades aragonesas de moros ante notarios cristianos para otorgar testamento; los hacían ante el alfaquí de la aljama a la que pertenecían. $Y$, sin duda, los exiguos medios de fortuna de los posibles testadores, aunque hubiera excepciones.

A ambas razones habría que añadir que no fueron muchas las conversiones que tuvieron lugar en el seno de las comunidades de moros si las comparamos con las que se produjeron en las comunidades de judíos, por lo que en los pocos documentos que a ellas aluden y en los testamentos encontrados de moros y conversos de sus comunidades, o en referencias a ellos, no son frecuentes las alusiones de unos a otros.

Aunque esas circunstancias hacen difícil aportar datos concluyentes sobre la posible relación de moros con conversos de sus comunidades, he encontrado cuatro instrumentos públicos notariales en los que aparece frecuente y más o menos amistosa la relación entre ellos, cuando existían lazos de sangre o amistad. Los cuatro documentos, base fundamental de este estudio, proceden de los Registros y Protocolos del notario de Zaragoza Pedro Serrano y se conservan en el Archivo de Protocolos Notariales de esa ciudad ${ }^{1}$.

1 Siglas, Z.APN.; a ellas seguirá el nombre del notario, año, folios y los nombres de los testigos instrumentales. Los nombres y apellidos de moros, que no acentúo, están es-

Al-Qanțara XXIV, 1 (2003) 169-178 
Se trata de referencias al testamento de Miri o Mira de Pina y al de Ibrahim de Junez, del testamento completo del converso Gil Pérez de Buisán y de la renuncia que de sus derechos hereditarios hizo el también converso Pedro Soriano, hijo de Hamet de Cepta. Miri e Ibrahim pertenecieron a la comunidad de moros de Zaragoza; Gil y Pedro habían formado parte de ella.

Miri de Pina estuvo casada con Ibrahim Embram. Del matrimonio no quedaron hijos, ya fuera porque nunca los hubo o porque no les sobrevivieron, pero ella tenía dos sobrinos carnales con su mismo apellido, uno converso y otro moro, los hermanos Salvador e Ibrahim de Pina.

Los dos hermanos Pina habían vivido en unas casas de la morería de Zaragoza, sitas «en el callyço que sallye al huerto de los frayres menores», que lindaban con las de «la Çedriqua», con las de Axa de Rondi, con las de Muça el Alamin y con carreras públicas.

El cambio de creencia religiosa no parece que hubiera entibiado la relación entre Salvador e Ibrahim de Pina, el cual contrajo matrimonio con Axa de Brea. De tal manera mantuvieron sus lazos de parentesco y amistad que ambos hermanos llegaron a un acuerdo sobre el reparto de los bienes que les pertenecían, el domingo 25 de julio de 1423, en Zaragoza.

Dicho día Ibrahim renunció en favor de su hermano converso a: «todo el qualquiere dreyto que yo he e haver puedo e devo» en las citadas casas de la demarcación de la parroquia de San Gil, «con todos los bienes mobles en aquellyas stantes». Pero Ibrahim impuso a Salvador una condición: «que dona Mira de Pina, mora tia nuestra, este durant tiempo de su bida. Et apres dias suyos que pueda posar e meter sobre las ditas casas pora obra de la mezquita aquel trehudo que a ellya sera bien visto».

Por su parte Salvador de Pina, «olim moro et agora por gracia de nuestro senyor Dios convertido a la fe catholica, renuncio, relexo e desemparo en» su hermano Ibrahim y en su cuñada Axa de Brea a: «todo e qualquiere dreyto que yo he e haver puedo e devo apres dias vuestros en otros bienes, assi mobles como sedientes, etc.» ${ }^{2}$.

Con ambos instrumentos públicos notariales el converso pasaba a ser propietario de las casas de la morería y de los bienes muebles que contenían, aunque su tía siguiera viviendo en ellas y pudiera gravarlas con un treudo perpetuo a favor de la mezquita, pero perdía cualquier derecho hereditario sobre los bienes de su hermano Ibrahim y de su cuñada Axa.

La falta de hijos de Miri de Pina y el cariño que sintiera por sus sobrinos Ibrahim y Salvador, debieron de aliviar su viudedad y la última enfermedad que acabó con su vida.

critos con la grafia de los documentos cuando van entrecomillados, igual que las palabras árabes que aparecen en cursiva.

2 Z.APN., Pedro Serrano, Reg. y Prot. 1423, fols. 35-36v y $147-147 v$, respectivamente: testigos, el notario Andrés Sanz y el moro Calema Albaraquer, ambos de Zaragoza. 
Un «sabado a cinquo dias de febrero anyo de huytientos e vint e siet anyos al conto de los moros», «viniendo a la muert» la viuda Miri, otorgó su último testamento en Zaragoza, «recebido e testifficado por Calema Alamaqui, alfaqui de la aljama de los moros» de la ciudad.

Entre otras cosas, Miri dejó cinco sueldos anuales «de almosna pora la mezquita clamada de Alquerqui», sobre las citadas casas, e instituyó herederos universales a sus sobrinos Ibrahim de Pina y Salvador de Pina.

Dividir los bienes muebles y parte de los inmuebles dejados por Miri a sus sobrinos no supondría ningún problema a los hermanos, pero Salvador tenía que hacer efectivo el treudo perpetuo instituido por su tía.

El 7 de febrero de 1425, en la ciudad, el converso se comprometió y obligó a pagar anual y perpetuamente, «justa la boluntat de la dita testadriz» Miri de Pina, cinco sueldos «pora la dista almosna a la dita mezquita et a los vezinos de aquellya, por el dia e fiesta de la pasqua de Romadam de los moros... o quatro dias antes». Salvador aseguró que: «por special pacto e condicion havido entre los ditos moros e mi quiero, atorgo e expressament consiento que yo ni los descendientes de mi ni quienquiere que por tiempo sera detenedor e posseydor de las ditas casas no pueda aquellyas ni partida de aquellyas dar, vender, empenyar, canviar, feriar, permutar ni en alguna otra manera alienar ni trasportar ni en especial obligar las ditas casas a persona alguna, sino ys con carga de los ditos cinquo solidos de almosna a la dita mezquita» ${ }^{3}$.

Aunque el compromiso de Salvador de respetar y hacer efectivo el treudo perpetuo instituido por su difunta tía Miri fue la última cuestión económica pendiente entre el converso y su hermano Ibrahim, no creo que a partir de entonces se enfriaran o cesaran las relaciones de ambos. Los dos hermanos Pina mantendrían los encuentros familiares y conversaciones por encima de sus creencias religiosas, como siempre lo habían hecho.

En este primer cuarto del siglo XV residieron también en la morería de Zaragoza Ibrahim de Junez, su mujer Axa de Pex y sus dos hijos. El matrimonio gozaba de una saneada situación económica y eran dueños de cuatro inmuebles en la ciudad.

Dos de sus casas estaban situadas en la demarcación de la parroquia de San Gil: unas lindaban «con casas de Jahiel de Rondi, con casas de Muça el Alamin e con carrera por do han entrada e sallyda»; las otras, «con casas de Johan Calbo, con casas de Johan de Perales e con carrera publica». El tercer inmueble estaba situado en la morería, «en el barrio clamado de Albarmaxitan», se encontraba libre de cargas y lindaba «con casas de Farax de Alcalahorri, con casas de Mahoma Romi e con carrera publica». El cuarto inmue-

${ }^{3}$ Siguen las acostumbradas fórmulas de garantía de esta clase de instrumentos públicos (Z.APN., Pedro Serrano, Reg. 1425, fols. 70v-71v: testigos, los zaragozanos Martín de Callén, el escribiente Francisco de Lafoz y el moro Calema Albaraquet). 
ble de Ibrahim y Axa era «una tienda, sita en la fusteria» de la ciudad, que lindaba «con tienda de Farax de Gali, con tienda de Juçe Xama e con carrera publica; con carga de siet sueldos de trehudo que faze en cada un anyo al senyor Rey».

Si la vida de Ibrahim de Junez y de Axa de Pex transcurría con normalidad, no ocurría lo mismo con la de otro miembro de la familia mora de los Junez, que desempeñaba el oficio de fustero; era hermano o sobrino de Ibrahim y estaba casado con Marien de Abenjacer o Abinjucer, de cuyo matrimonio había nacido un hijo, Mahoma de Junez.

Un grave suceso empañaba y entristecía la vida de Marien y la de su hijo Mahoma. La estabilidad de su matrimonio empezó a tambalearse cuando el fustero pensó convertirse «a la fe catholica».

Nada se sabe de las dudas religiosas que le asaltaron hasta terminar con el abandono de su «ley» religiosa, pero los frailes del monasterio de Santa María del Carmen de Zaragoza, en especial fray Pedro Palmer, debieron de influir en su ánimo y conciencia, hasta conseguir su conversión, de la que tampoco debió ser ajeno el ciudadano don Gil Pérez de Buisán, que muy posiblemente actuó como padrino.

Una vez bautizado el fustero con el nombre y apellido de Gil Pérez de Buisán y ante la negativa de Marien a secundarlo, el matrimonio se separó.

No constan las condiciones del pacto de ruptura matrimonial, ni en que situación económica quedaron Marien y su hijo Mahoma de Junez, pero a partir de entonces madre e hijo continuarían su vida en la comunidad de la que formaban parte, siguiendo su relación con Ibrahim de Junez, su mujer Axa de Pex y sus dos hijos, parientes de Gil.

El converso, quizás preocupado por el futuro de su abandonada familia, tenía que dejar la morería para pasar a formar parte de la comunidad cristiana. En ella y como miembro de la misma, ejerció su oficio de fustero y contrajo segundas nupcias con Palaziana la Crespa, oriunda de Tarazona, según parece.

El tiempo siguió su inexorable curso e Ibrahim de Junez, posiblemente enfermo, viudo y con dos hijos menores de edad, decidió otorgar su última voluntad. Su testamento fue «feyto en Caragoca dia sabado en la primera dezena del mes de exaguel anyo de DCCC e XXII, al conto de los moros, por Calema Alamaquel, alfaqui de la moreria de la ciudat de Çaragoca e scrivano de la alcadia de aquellya». Como sus dos hijos pupilos quedarían sin amparo a su muerte, Ibrahim nombró al moro Ali de Rondi tutor y curador testamentario de la persona y bienes de su hija Axa de Junez y quizás también de su hijo.

No consta si fue la orfandad del hijo de Ibrahim y de Axa, la conversión de su pariente Gil, su influencia y la mediación del citado fray Pedro Palmer, las causas que llevaron al bautismo del menor con el nombre de Juan Pérez de Buisán, sin que su hermana Axa de Junez lo secundara. 
Cuando el pequeño converso Juan pasó a formar parte de la comunidad cristiana, necesitó un tutor y curador de su persona y bienes que perteneciera a su misma fe religiosa. Juan tenía un familiar cercano que podía desempeñar esa función, Gil Pérez de Buisán y, siguiendo una costumbre habitual, su nombre debió de proponerse al zalmedina de Zaragoza, encargado de nombrar tutores y curadores dativos en la comunidad cristiana.

La designación y asignación de Gil Pérez de Buisán para desempeñar la función de tutor y curador del menor Juan Pérez de Buisán, la hizo el zalmedina Pedro Sánchez de Tapalbo el 6 de noviembre de 1422, en la ciudad ${ }^{4}$.

Habían transcurrido dos meses y unos días de esta designación cuando el converso Gil, tutor y curador dativo de la persona y bienes de su «nieto» ${ }^{5}$ converso Juan Pérez de Buisán, y el moro zaragozano Ali de Rondi, tutor y curador testamentario de la persona y bienes de Axa de Junez, llegaron a un acuerdo sobre la partición de bienes de los hermanos.

El 10 de enero de 1423, en la ciudad, ambos tutores y curadores reconocían «seyer benidos a buena, verdadera e leal particion de todos los bienes, assi mobles como sedientes, los quales finquaron comunes, indivisos e por partir entre los ditos pupillyos por muert e succession de los ditos Ybrahim de Junez e Axa de Pex».

En la partición, correspondieron al menor Juan Pérez de Buisán las dos casas de Ibrahim y de Axa, situadas en la demarcación de la parroquia de San Gil, además de «todos los bienes mobles que fueron de los ditos su padre e madre, los quales son scriptos en el livro del alcadi de la dita moreria de Caragoça». Y correspondieron a la pupila Axa la tienda descrita de Ibrahim y de Axa, además de las casas de sus padres sitas en la morería, «en el barrio clamado de Albarmaxitan, franquas e quitas».

Una vez asignados los bienes a cada uno de los menores, sus tutores y curadores Gil y Ali manifestaron: «con los quales bienes mobles e sedientes de la part de suso nombrados, especifficados e declarados, a cada una de nos ditas partes toquantes, atorgamos en los ditos nombres e cada uno dellyos e reconoscemos en verdat seyer bien e entregament pagados e contentos de la dita particion; por aquesto renunciantes cada uno de nos, en los ditos nombres e cada uno dellyos, a toda excepcion de frau e de enganyo e de no haver recebido cada uno de nos ditos tutores su part toquant de los ditos bienes mobles e sedientes e de no seyer feyta legitimament e segunt fuero la present particion, de la scoba entro a la cenisa del fogar» ${ }^{6}$.

${ }^{4}$ «Signada por mano de Bernart de Lerses... e por Anton Rol, notario publico por toda la tierra e senyoria del illustre senyor Rey de Aragon e sellada con el siellyo inpedint de la cort del dito çalmedina».

5 Palabra que también se empleaba para designar al sobrino carnal.

${ }^{6}$ Luego se absolvieron mutuamente «de todas e qualesquiere demandas, questiones e peticiones reales e personales..., por razon de los ditos bienes mobles e sedientes, los quales pertenecian a cada uno de los ditos pupillyos... Est por mayor firmeza e seguridat 
A partir de ese momento las vidas de Axa de Junez y de su hermano Juan deberían separarse para siempre. Se relacionaran o no, los menores pertenecían a dos mundos religiosos diferentes. Ella formaba parte de una comunidad mora, la misma del tutor de su persona y curador de sus bienes; él de una cristiana, igual que su tutor y curador.

No consta que destino dio el tutor y curador testamentario Ali de Rondi a los inmuebles de la pupila Axa de Junez, pero si lo que hizo el tutor y curador dativo Gil Pérez de Buisán con los que le correspondieron al pupilo Juan.

A los cinco meses de la partición de bienes entre Axa y su hermano, concretamente el lunes 7 de junio, el converso Gil Pérez de Buisán manifestó que unas de las casas de Ibrahim y de Axa que en la partición pasaron a ser propiedad del menor converso Juan Pérez de Buisán, del que era tutor y curador dativo, las situadas «en el barrio clamado del Alquerqui» de la morería ${ }^{7}$, se encontraban «dirruydas», «derroquadas e malparadas, de manera que a reparar e adobar aquellyas no bastarian los bienes» del menor; y que además estaban situadas «entre moros e infieles et al fiel christiano no convienga estar e habitar entre infieles, mayorment ad aquellyos que de la dita secta se sian convertidos a la fe berdadera e cristiana». Gil explicó luego que por esas y «por otras justas razones» había resuelto venderlas a su convecino moro Muça el Alamin por trece florines y medio de oro, cantidad que otorgó haber recibido con el alifara, etc.».

El tutor y curador dativo Gil Pérez de Buisán justificó la venta especificando que lo hacía: «por bien avenir del dito pupillyo et pora sustentacion de aquel, como al present no se troben otros bienes tan espedientes pora criar, alimentar e proveyr aquel como aquestas casas». Pero a continuación, también vendió a sus convecinos moros Jahiel de Rondi e Ibrahim de Rondi, por trece florines, las otras casas del pupilo ${ }^{8}$ con su corral ${ }^{9}$.

Había transcurrido un año de la venta de las casas del menor, por las que su tutor y curador recibió veintiséis florines y medio, que servirían «pora

de nos ditas partes e de cada una de nos et de los ditos pupillos (sic) damos fiança de riedra de la present particion, segunt fuero de Aragon..., a Paschual de Monrreal, alias de Cordova, aguardentero vezino de la dita ciudat, qui present yes. Et yo dito Paschual de Monrreal..., en mi nombre propio, por cada una de las ditas partes tal fiança de riedra me atorgo seyer, segunt dito ys de suso, dius obligacion de todos mis bienes mobles e sedientes, havidos e por haver en todo lugar» (Z.APN., Pedro Serrano, Reg. 1423, fols. 8-10: testigos, el escudero Juan de Cantaniella y el moro Juçe Palacio, ambos de Zaragoza).

7 Lindaban con las de Juan Calbo, con las de Pedro Toledo, con corral del mismo pupilo y con carrera pública; así aparecen los linderos en este instrumento.

${ }^{8}$ Lindaban con las del citado Muça y con las de dicho Jahiel.

9 Lindaba con las casas de Muça, con las de Juan Calvo y con carrera. Gil dio toda clase de garantías en las ventas (Z.APN., Pedro Serrano, Reg. y Prot. 1423, fols. $117-119 v$ y $118 \mathrm{v}-119$, respectivamente: testigos, Juan del Villar y Ximeno Pérez de Artaso, notarios y ciudadanos de Zaragoza). 
criar, alimentar e proveyr aquel», cuando el converso Gil Pérez de Buisán compareció de nuevo ante notario.

Lo hizo el viernes 11 de agosto de 1424, en la ciudad, para manifestar lo siguiente: «de mi cierta sciencia absuelvo, suelto, quito, lexo relexo e del todo pora siempre deffenezco a bos Jahiel de Rondi... de todas e qualesquiere quantias de dineros e florines, joyas e qualesquiere otras cosas e bienes que bos fuessedes tenido de dar e pagar a mi o a Marien de Abinjucer, muller mia quondam, en todo el tiempo passado daquia el present dia de huey con cartas e sines cartas e en qualquiere otra manera, assi que de aqui adelant yo ni otri por mi question alguna ni demanda no vos faga ni fervos faga ni pueda en judicio ni fuera» ${ }^{10}$.

Es posible que el converso Gil Pérez de Buisán todavía se ocupara de la «sustentacion» de su pupilo Juan en su propio domicilio, cuando cayó enfermo. Habían transcurrido tres años de la venta de las casas del menor, sin que se sepa si éste había alcanzado la mayoría de edad y si su tutor y curador dativo le había dado cuenta de la administración de su herencia.

El 29 de marzo de 1426, en Zaragoza, el converso Gil Pérez de Buisán se encontraba ante notario para otorgar testamento. Lo empezó del mismo modo que lo hubiera hecho un cristiano: «En el nombre de nuestro senyor Dios e de la gloriosa birgen senyora Santa Maria, madre suya, sian Amen. Por tal que la bida de aqueste mundo ys incierta e enganyosa e en el mundo no haya tan cierta cosa como la muert ni mas incierta que la hora de aquellya e alguna persona en carne puesta a la muert corporal escapar non pueda, por aquesto sepan todos como yo..., estando enfermo empero por gracia de nuestro senyor Dios en mi buen seso, firme memoria e palavra manifiesta, temiendo las crueles penas del infierno e deseando yr a la santa gloria de paradiso, cassando, revocando e anullando todos los otros testamentes, codicillyos e hordinaciones por mi ante de agora feytas e hordenadas, fago e hordeno aqueste mi ultimo testament e çaguera boluntat e hordinacion de todos mis bienes, assi mobles como sedientes, por tal que cada e quando a

10 «Et si lo fazia que no haya balor ni firmeza mas que si feyta non fuesse, imponient a mi e a los mios en e cerqua las ante ditas cosas perpetuo silencio e callamiento. Et en testimonio de lo sobre dito fagobos ende fer aqueste present publico albaran de diffinimiento, absolution e quitamiento a todos tiempos firme e valedero» (Z.APN., Pedro Serrano, Prot. 1424, fols. 128v-129: testigos, el calderero Alfonso de Fromesta y el alfaquí de Zaragoza Calema Alamaqui). Un año largo antes, concretamente el martes 30 de marzo de 1423, "Çalema Alamaquy, moro alfaqui de la aljama de moros» de la ciudad, iba a actuar como procurador de Juçe Abenamir, hijo del difunto moro de Pedrola Ali Abenamir, de Mahoma Marquan, hijo de Juçe Marquan, y de los moros de Borja Mahoma de Bicas, mayor de días, y Ezmael de Adumelch, que habían comprado a «Mahomer Abenali, alias Alnalaqui, por cativo e servidor» (dicho notario, Prot. 1423, fol. 63; el instrumento no termina: testigos, el notario Miguel de Campos y el moro Jahiel de Gali). La compra de cautivos por parte de las aljamas de moros para conseguir su libertad, como en el caso de Mahomer, era un hecho habitual. 
nuestro senyor Dios plazera que yo deva passar e passe de aqueste mundo al otro, entre mi fillyo, mis parientes mas çerquanos e mi heredero universal diuso scripto, por razon de mis bienes contencion alguna non pueda seyer havida ni movida, antes quiero, mando e hordeno que aquel sia exsiguido e complido en todo e por todas cosas como e segunt yo aqui lo hordeno»:

«Primerament slio mi sepultura en el monesterio de senyora Santa Maria del Carmen, alli do sera bien visto a mis spondaleros diuso scriptos. Et quiero e mando que de mis bienes sia feyta mi deffunssion hondradament segunt que a mi conviene, novena e cabo de novena».

Ordena que sus ejecutores testamentarios vendan: «toda mi ferramiente de fusteria e del precio de aquellya sian satisfeytos, pagados e emendados todos mis deudos, tuertos e injurias, aquellyos e aquellyas que por berdat seran trobados yo seyer tenido, con cartas e menos de cartas o en qualquiere otra manera».

Dejo: «por legitima herencia de todos mis bienes, assi mobles como sedientes, a Mahoma de Junez, fillyo mio legitimo e de Marien de Abenjacer, mullyer mia qui fue, cinquo sueldos dineros jaqueses por todo moble e una rova de tierra en el mont por todo sedient, con los quales se tienga por contento e pagado de toda e qualquiere part e legitima que el pudiesse haver, demandar e alcançar de mis bienes e mas haver, demanda e alcançar non pueda».

Dejo: «por reverencia de Dios e en remission de mis peccados al monesterio de senyora santa Maria del Carmen..., por tal que rueguen a Dios por mi anima, aquellyos vint e tres florines de oro los quales Palaziana la Crespa, mullyer mia, me firmo sobre todos sus bienes, assi mobles como sedientes e en special sobre unas casas», sitas en Tarazona, «en el tiempo que yo contraye matrimonio con ellya».

El converso instituyó al citado don Gil Pérez de Buisán, con el que no especificó parentesco alguno, heredero universal de «todos los otros bienes mios, assi mobles como sedientes e por si movientes, que yo he e a mi convienen e pertenescen e convenir e pertenescer pueden e deven por qualquiere dreyto, titol, succession, caso, manera o razon, de los quales yo en aqueste mi ultimo testament no he feyto ni fago special mencion, los quales bienes quiero aqui por tanto seyer hovidos como si los mobles fuessen aqui por sus nombres nombrados, specifficados e declarados e los sedientes por una, dos o tres confrontaciones mas o menos confrontados, designados e limitados todos». También nombró a don Gil su ejecutor testamentario, junto con el citado fraile Pedro Palmer; a ambos dio pleno poder para «exseguir e complir» su testamento.

Finalmente, el converso quiso que su testamento valiera «por dreyto de testament o por dreyto de codicillyo o por qualquiere otro dreyto, caso, manera o razon de ultima voluntat puede e deve baler segunt fuero, uso e costumbre del regno de Aragon». 
Que ni siguiera Gil la nombrara en su testamento, no fue del agrado de su mujer. Palaciana la Crespa no dio su consentimiento al testamento de su marido, protestó e hizo la siguiente manifestación: «que me finquen mis dreytos salvos e illesos en todo e por todas cosas, do quiere que trobados seran» ${ }^{11}$.

Si Gil sólo dejó a su hijo Mahoma, el único que tenía, una asignación de bienes que no podía estar más ajustada a la legítima foral, no puede extrañar que tampoco nombrara en su testamento al pupilo converso Juan Pérez de Buisán, hubiera o no alcanzado su mayoría de edad. A juzgar por lo que parece que se ocupó de Mahoma, no le dedicaría mayor atención a ese otro niño, Juan, al que también le unían lazos de sangre y del que había sido tutor dativo de su persona y curador dativo de sus bienes.

Años después el desasosiego y la tristeza que acarreaba una conversión hacían acto de presencia en otra familia de la aljama de moros de Zaragoza. Se trataba del hijo de Hamet de Cepta, que se bautizó con el nombre de Pedro Soriano, mientras su hermano Farax de Cepta permanecía fiel a su credo religioso.

El bautismo de Pedro no debió de aminorar el cariño y afecto que sintiera por su familia y, sobre todo, por su hermano Farax.

Después de la muerte de Hamet, su hijo converso Pedro Soriano comparecía ante notario el sábado 2 de abril de 1440, en la ciudad, y manifestaba lo siguiente: «renuncio, relexo e desemparo a vos e en vos Farax de Cepta, mi hermano moro..., todo e qualquiere dreyto que yo he e haver puedo e devo en los bienes, assi mobles como sedientes que fueron del dito mi padre, assi sitos e estantes en Caragoca e sus terminos como en otro lugar. Et con aquesto bos absuelvo, suelto, quito, lexo, relexo e del todo pora siempre deffenezco e por suelto, quito e diffinido do a vos dito Farax de todas e qualesquiere questiones e demandas, assi civiles como criminales, etc. que yo bos pudiesse fazer, assi por razon de qualesquiere quantias de dineros e florines e otras cosas e bienes que bos me deviessedes dar, assi por muert del dito mi padre como en qualquiere otra manera, de todo el tiempo passado daquia el present dia de huey con cartas e sin cartas, etc. assi que de aqui adelant question alguna ni demanda no vos faga ni pueda, etc. imponient a mi e a los mios, etc. silencio perpetuo e callamiento et en testimonio, etc. fago vos de fer aqueste albaran e diffinimiento, etc.» ${ }^{12}$.

Una vez terminado este trabajo y después de su lectura, Miri de Pina y sus sobrinos, los hermanos Salvador e Ibrahim de Pina, al igual que Pedro Soriano, se muestran, a mi juicio, como personas agradecidas y con fuertes

11 Z.APN., Pedro Serrano, Reg. y Prot. 1426, fols. 1-2v y 56v, respectivamente: testigos, Antón de Agraz y el escribiente Martín Berrueco, vecinos de la ciudad.

12 Z.APN., Pedro Serrano, Prot. 1440, fols. 81-81v: testigos, el sastre Juan de Salvatierra y el moro Mahoma Certin, ambos de Zaragoza. 
lazos familiares, pese a haberse producido en el seno de sus familias una conversión. Por el contrario, los instrumentos públicos notariales en los que intervino Gil Pérez de Buisán y lo que a través de ellos se percibe de su personalidad, muestran al converso frío, calculador y con escasos afectos. 